\title{
SURFACTANT-ASSISTED SOL-GEL AUTO-COMBUSTION SYNTHESIS OF SR-HEXAFERRITE NANOPOWDER USING DIFFERENT FUELS AND BASIC
}

\author{
AGENTS \\ M. GHOBEITI HASSAB \\ Center of Excellence in Magnetic Materials, School of Metallurgy and Materials, University of Tehran, \\ Tehran 11155 4563, Iran \\ mghasab@engmail.ut.ac.ir \\ S. A. SEYYED EBRAHIMI ${ }^{1}$ \\ Center of Excellence in Magnetic Materials, School of Metallurgy and Materials, University of Tehran, \\ Tehran 11155 4563, Iran \\ saseyyed@ut.ac.ir

\section{R. DEHGHAN} \\ Center of Excellence in Magnetic Materials, School of Metallurgy and Materials, University of Tehran, \\ Tehran 11155 4563, Iran \\ rdehghan@ut.ac.ir
}

\begin{abstract}
In this research Sr-hexaferrite powder was synthesized by a sol-gel auto-combustion route using two different fuels (glycine and citric acid) and two different basic agents (ammonia and trimethylamine). N-decyltrimethylammonium bromide $\left(\mathrm{C}_{13} \mathrm{H}_{30} \mathrm{BrN}\right)$ was also employed as a cationic surfactant. The results showed the finest crystallite size and the lowest calcination temperature have been obtained as $27.2 \mathrm{~nm}$ and $800{ }^{\circ} \mathrm{C}$ respectively, in the presence of citric acid, trimethylamine and surfactant.
\end{abstract}

Keywords: Nano Powder, Sol-Gel Auto-Combustion, Sr-Hexaferrite, Surfactant.

\section{Introduction}

Sr-hexaferrite is a magnetic ceramic with a wide range application as a permanent magnet and magnetic recording media because of its suitable hard magnetic properties, high Curie temperature and chemical stability. ${ }^{1}$

Sol-gel auto-combustion synthesis is a novel technique for producing this material with ultra fine particles using an exothermic reaction between metal nitrates and an organic fuel in a short time without need to the high temperature furnace and prolonged ball milling. ${ }^{2-4}$

\footnotetext{
${ }^{1}$ Corresponding Author
} 
Addition of cationic surfactant with molecules composed from the hydrophilic head and hydrophobic tail, into precursor solution results in formation of reverse micelles in the gel. Placing the aqueous ions inside these micelles can be effective for controlling the growth of the particles. Surfactant has also the role of fuel in the combustion process. ${ }^{5,6}$

The powder characteristics like crystallites size, particles morphology and agglomeration are dependent on flame temperature generated during combustion, which itself is dependent on nature of the fuel and other starting materials such as oxidant and $\mathrm{pH}$ adjusting agents. ${ }^{7,8}$

In this research, comparison of the formation temperatures and crystallites size of Srhexaferrite powders synthesized by the surfactant-assisted sol-gel auto-combustion method in the presence of different fuels and basic agents have been studied.

\section{Experimental}

Ferric nitrate and strontium nitrate powders in the molar ratio of $\mathrm{Fe} / \mathrm{Sr}=10$ were dissolved in distilled water. Fuel was added for the formation of metallic complexes, in an equal molar ratio with total moles of metal nitrates. For stability of complexes solution it was adjusted to $\mathrm{pH}=7$ for citric acid and 2 for glycine by adding trimethylamine and ammonia. Then, n-decyltrimethylammonium bromide was added (with molar ratio of surfactant to strontium: 0.4). The solution was heated on a hot plate. After drying, all samples ignited automatically. Upon ignition, the obtained ashes were ground and then calcined to form the Sr-hexaferrite phase.

The phase identification was carried out using X-ray diffraction (XRD) with $\mathrm{Cu}-\mathrm{K} \alpha$ radiation. The particles size and morphology were examined by a scanning electron microscope (SEM) and a transmission electron microscope (TEM). Crystallites size of the powders was estimated on base of the XRD data of main peak using sherrer's formula.

\section{Results and Discussion}

Figs. 1, 2 and 3 show the combustion process of samples synthesized using various fuels and basic agents with and without surfactant.

The combustion process is more sever in sample with trimethylamine and surfactant. Trimethylamine and surfactant are both organic components and in the combustion process they produce a large volume of gases. The resultant ash in these samples is also more voluminous. 


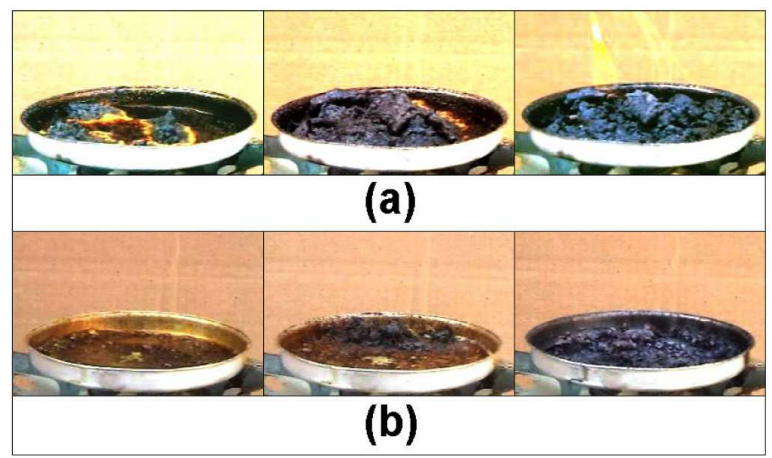

Fig. 1. Self-propagated combustion stages of the samples prepared using fuels of (a) citric acid and (b) glycine, with trimethylamine and without surfactant.

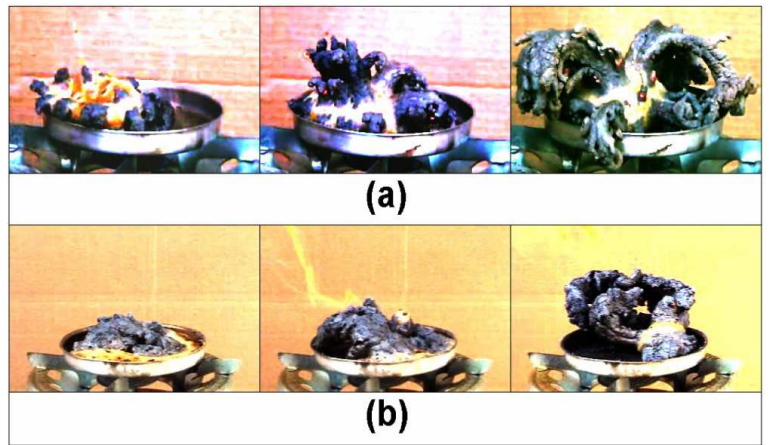

Fig. 2. Self-propagated combustion stages of the samples prepared using fuels of (a) citric acid and (b) glycine, with trimethylamine and in presence of surfactant.

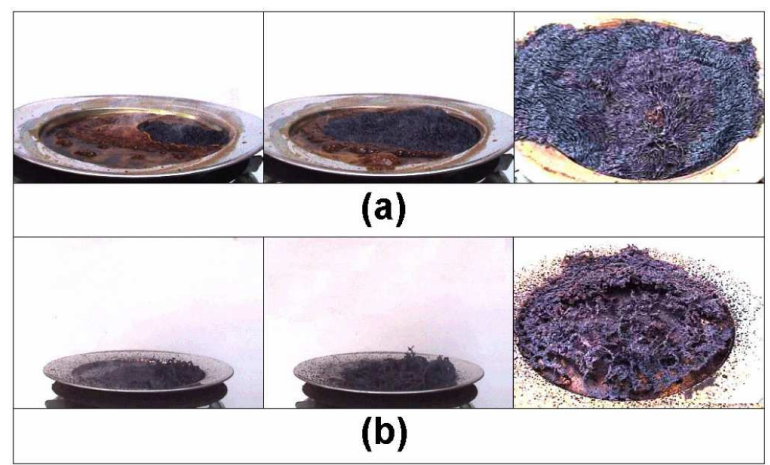

Fig. 3. Self-propagated combustion stages of the samples prepared using fuels of (a) citric acid and (b) glycine, with ammonia and in presence of surfactant. 
Figs. 4 and 5 show the XRD patterns of the powders synthesized using different fuels and basic agents in the presence of surfactant and without it.

According to these results, the formation temperature of Sr-hexaferrite single-phase is lower in the presence of trimethylamine and surfactant while fuel type has no effect on it. Since trimethylamine contains the organic compound instead of hydrogen of ammonia, it has also a role of fuel and the reactions leading to formation of Sr-hexaferrite will be done completely at lower temperatures. This is happened similarly in the presence of surfactant.

Crystallites size of the strontium hexaferrite powders which were calculated using the Scherrer formula, are indicated in Tables 1 and 2. Although formation temperature of Srhexaferrite single-phase in samples with fuels of citric acid and glycine is equal but there is a difference between their crystallite sizes. Citric acid is a more effective complexing agent than glycine in producing the more porous and finer powder which can be seen in Fig. 6. The temperature and time of calcination are selected high enough for a more clear comparison.

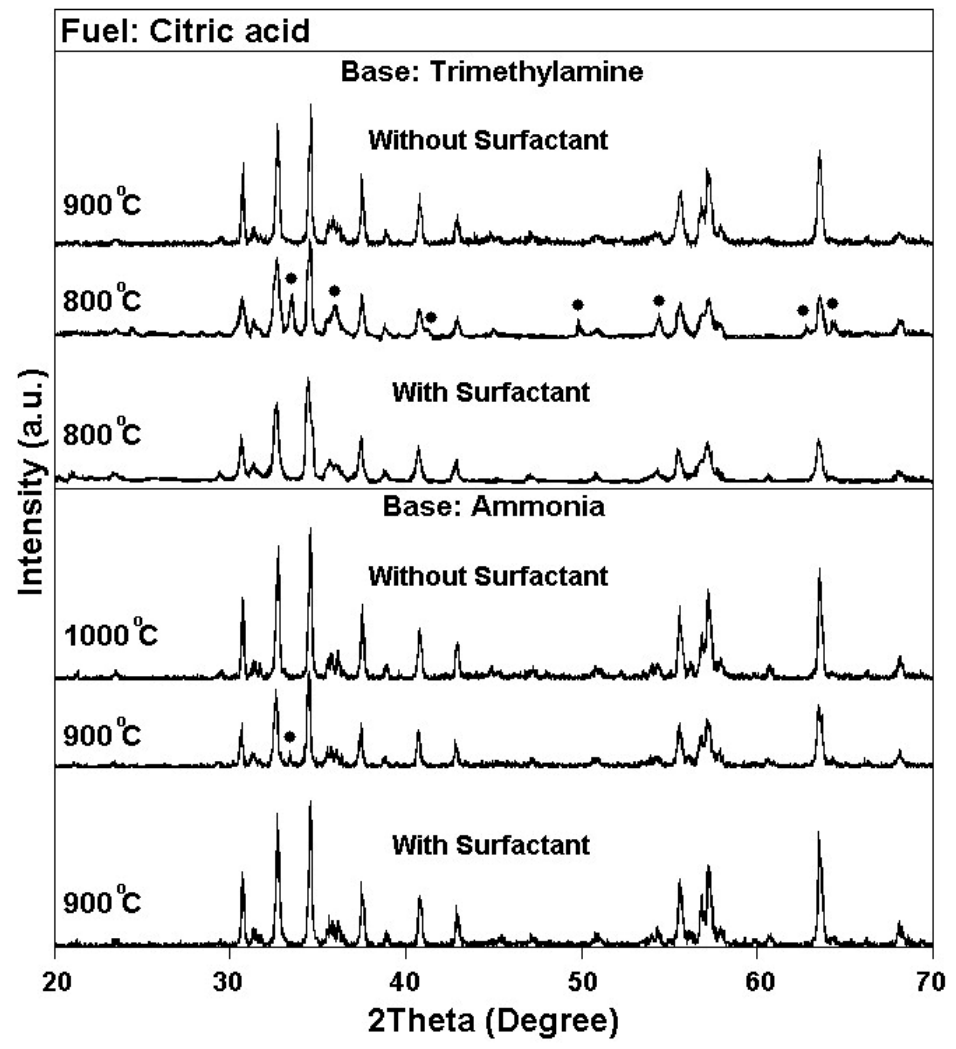

Fig. 4. XRD patterns of the powders synthesized using citric acid as fuel and different basic agents, with and without surfactant $\left(\bullet: \alpha-\mathrm{Fe}_{2} \mathrm{O}_{3}\right)$. 


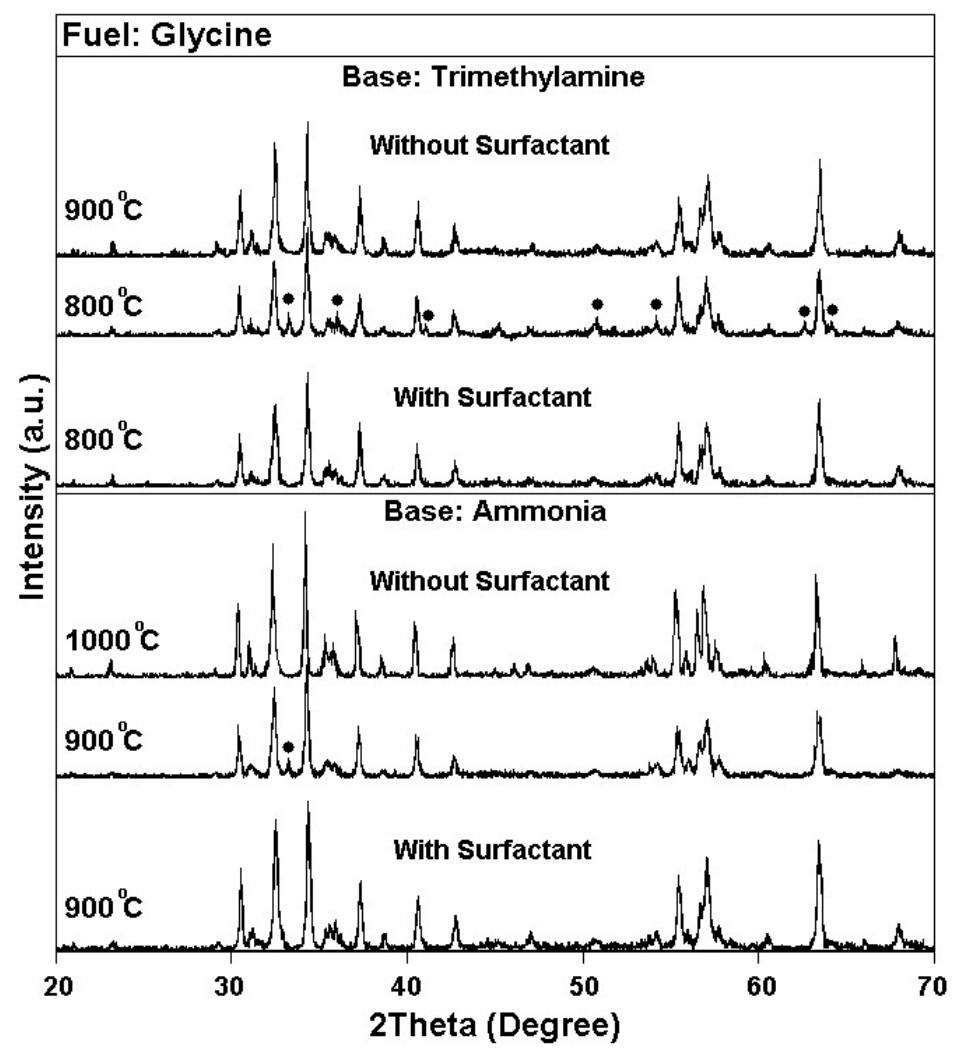

Fig. 5. XRD patterns of the powders synthesized using glycine as fuel and different basic agents, with and without surfactant $\left(\mathbf{O}: \alpha-\mathrm{Fe}_{2} \mathrm{O}_{3}\right)$.

Fig. 7 shows the SEM micrograph of the samples synthesized with citric acid and ammonia in the presence of surfactant and without it, which have calcined at $1100{ }^{\circ} \mathrm{C}$ for 3 hours. In these figures plate-like and hexagonal morphology of the particles could be observed. It is also deduced that the surfactant has a role of particles size controller. Much finer particles are more reactive and need to the lower temperatures for the formation of the final phase.

Fig. 8 shows the SEM micrograph of the samples synthesized with citric acid and surfactant in the presence of trimethylamine and ammonia basic agents, calcined at 1100 ${ }^{\circ} \mathrm{C}$ for 3 hours. Particles size in the sample contains trimethylamine is finer. More removal gases released from the ignition of the trimethylamine resulted in a finer powder. Fig. 9 shows the TEM photograph of the sample synthesized using the citric acid, surfactant and trimethylamine calcined at $800{ }^{\circ} \mathrm{C}$ for 1 hour. As it is seen, this powder is completely nanocrystalline. 
Table 1. Crystallites size and formation temperature of $\mathrm{Sr}$ - hexaferrite synthesized using citric acid at various conditions.

\begin{tabular}{llll}
\hline \hline Base & Surfactant & $\begin{array}{l}\text { Formation } \\
\text { Temp. }\end{array}$ & $\begin{array}{l}\text { Crystallite } \\
\text { size }\end{array}$ \\
\hline Ammonia & Not added & $1000{ }^{\circ} \mathrm{C}$ & $50.6 \mathrm{~nm}$ \\
Trimethylamine & Not added & $900^{\circ} \mathrm{C}$ & $46.7 \mathrm{~nm}$ \\
Ammonia & Added & $900{ }^{\circ} \mathrm{C}$ & $37.3 \mathrm{~nm}$ \\
Trimethylamine & Added & $800^{\circ} \mathrm{C}$ & $27.2 \mathrm{~nm}$ \\
\hline \hline
\end{tabular}

Table 2. Crystallites size and formation temperature of Sr- hexaferrite synthesized using glycine at various conditions.

\begin{tabular}{llll}
\hline \hline Base & Surfactant & $\begin{array}{l}\text { Formation } \\
\text { Temp. }\end{array}$ & $\begin{array}{l}\text { Crystallite } \\
\text { size }\end{array}$ \\
\hline Ammonia & Not added & $1000^{\circ} \mathrm{C}$ & $61.3 \mathrm{~nm}$ \\
Trimethylamine & Not added & $900^{\circ} \mathrm{C}$ & $53.2 \mathrm{~nm}$ \\
Ammonia & Added & $900^{\circ} \mathrm{C}$ & $49.4 \mathrm{~nm}$ \\
Trimethylamine & Added & $800^{\circ} \mathrm{C}$ & $38.1 \mathrm{~nm}$ \\
\hline \hline
\end{tabular}

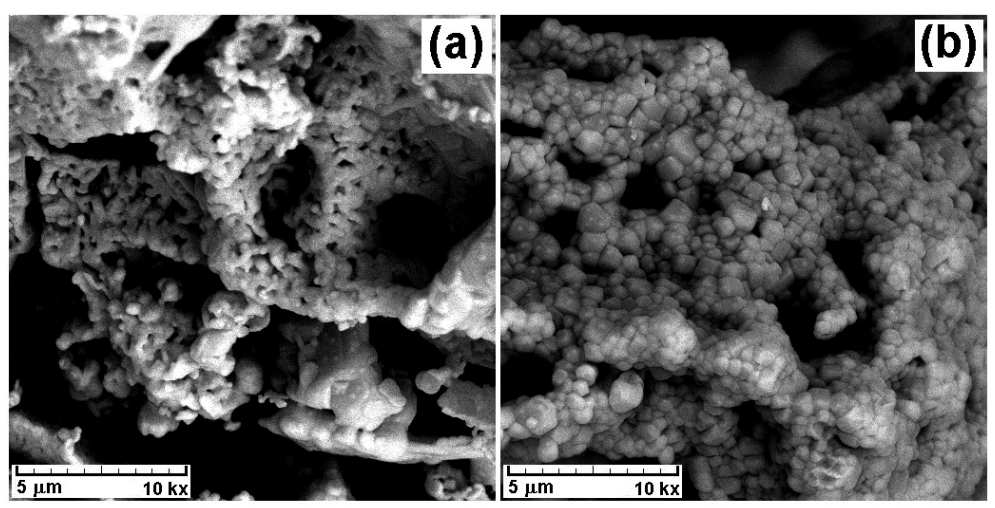

Fig. 6. Comparison of the size of the powder synthesized using (a) citric acid and (b) glycine, calcined at 1100 ${ }^{\circ} \mathrm{C}$ for $3 \mathrm{~h}$. 

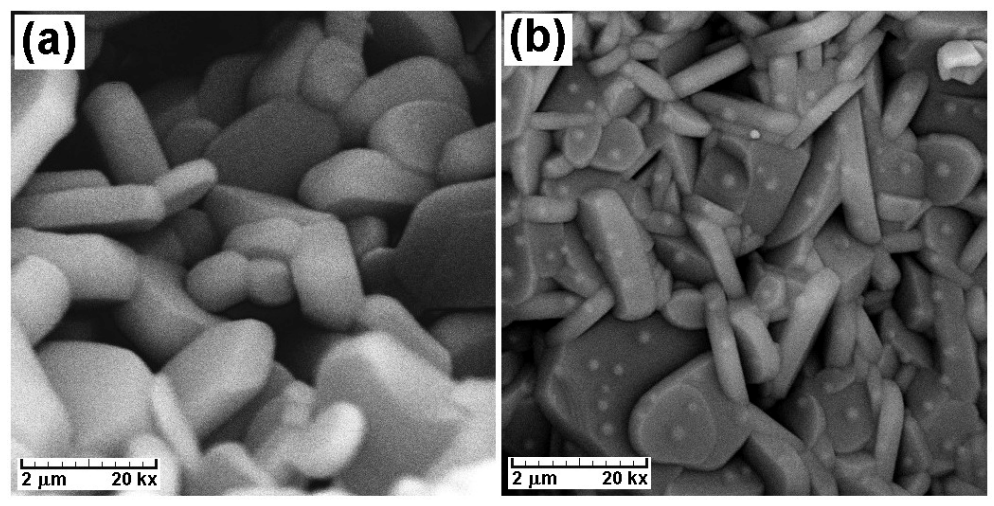

Fig. 7. SEM micrograph of the samples synthesized in presence of citric acid and ammonia, (a) without surfactant and (b) with surfactant, calcined at $1100{ }^{\circ} \mathrm{C}$ for $3 \mathrm{~h}$.
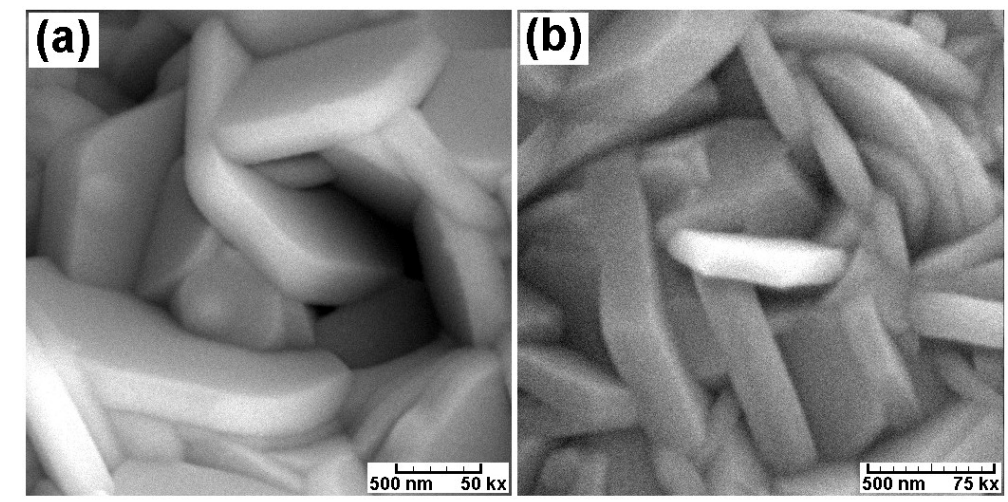

Fig. 8. SEM micrograph of the samples synthesized in presence of citric acid and surfactant, with (a) ammonia and (b) trimethylamine, calcined at $1100{ }^{\circ} \mathrm{C}$ for $3 \mathrm{~h}$.
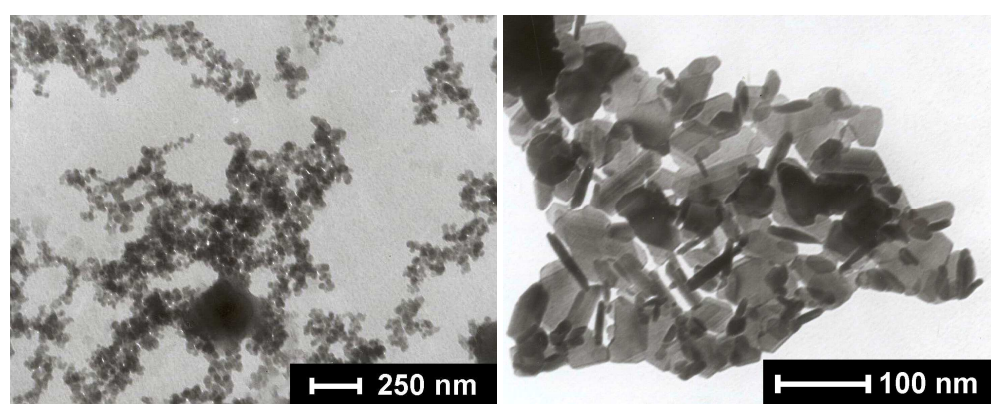

Fig. 9. TEM photograph of the sample synthesized using the citric acid, surfactant and trimethylamine, calcined at $800^{\circ} \mathrm{C}$ for $1 \mathrm{~h}$. 


\section{Conclusion}

Sr-hexaferrite nanopowder was synthesized by a sol-gel auto-combustion route using two fuels glycine and citric acid, and two basic agents, ammonia and trimethylamine, in the presence of surfactant of n-decyltrimethylammonium bromide. The results showed that:

1. The powder synthesized using citric acid is finer than the powder synthesized using glycine.

2. Using trimethylamine instead ammonia reduced the formation temperature of Sr-hexaferrite phase because of its alkyl groups which acts as an excess fuel, furthermore because of more removal gases from its ignition, the resultant powder is finer and more porous.

3. The surfactant results also in the decreasing of the particles size. Reduction the particles size in the presence of surfactant reduces also the needed calcination temperature for the formation of Sr-hexaferrite phase.

Therefore, with using citric acid, trimethylamine and surfactant, the crystallite size and the formation temperature of Sr-hexaferrite could be reduced to $27.2 \mathrm{~nm}$ and 800 ${ }^{\circ} \mathrm{C}$, respectively.

\section{References}

1. J.M.D. Coey, J. Magn. Magn. Mater., 248, 441 (2002).

2. M. R. Barati, S. A. Seyyed Ebrahimi, R. Dehghan, IEEE Trans. Mag., 45(6), 2561-2564 (2009).

3. M. R. Barati, S.A. Seyyed Ebrahimi and A. Badiei, Int. J. Modern Phys. B, 22(18\&19), 31593164 (2008).

4. M. R. Barati, S.A. Seyyed Ebrahimi, A. Badiei, J Non-Cryst Sol., 354(47-51), 5184-5185 (2008).

5. S. Allamolhoda, S.A. Seyyed Ebrahimi, A. Badiei, J. Magn. Magn. Mater, 303, 69 (2006).

6. M. Ghobeiti Hasab, S.A. Seyyed Ebrahimi and A. Badiei, J. Mag. Mag. Mat., 316, e13-e15 (2007).

7. M. Ghobeiti Hasab, S.A. Seyyed Ebrahimi and A. Badiei, J. Euro. Ceram. Soc., 353, 802-804, (2007).

8. M. Ghobeiti Hasab, S.A. Seyyed Ebrahimi and A. Badiei, J. Non-Cryst. Sol., 353, 814-816, (2007). 